University of Nebraska - Lincoln

DigitalCommons@University of Nebraska - Lincoln

2010

Biointeraction analysis by high-performance affinity chromatography: Kinetic studies of immobilized antibodies

\author{
Mary Anne Nelson \\ University of Nebraska - Lincoln \\ Annette C. Moser \\ University of Nebraska-Lincoln, moserac@unk.edu \\ David S. Hage \\ University of Nebraska - Lincoln, dhage1@unl.edu
}

Follow this and additional works at: https://digitalcommons.unl.edu/chemistryhage

Part of the Chemistry Commons

Nelson, Mary Anne; Moser, Annette C.; and Hage, David S., "Biointeraction analysis by high-performance affinity chromatography: Kinetic studies of immobilized antibodies" (2010). David Hage Publications. 3. https://digitalcommons.unl.edu/chemistryhage/3

This Article is brought to you for free and open access by the Published Research - Department of Chemistry at DigitalCommons@University of Nebraska - Lincoln. It has been accepted for inclusion in David Hage Publications by an authorized administrator of DigitalCommons@University of Nebraska - Lincoln. 


\title{
Biointeraction analysis by high-performance affinity chromatography: Kinetic studies of immobilized antibodies
}

\author{
Mary Anne Nelson, Annette Moser, and David S. Hage \\ Chemistry Department, University of Nebraska-Lincoln, 704 Hamilton Hall, Lincoln, NE 68588-0304 \\ Corresponding author - D. S. Hage, el 402 472-2744, fax 402 472-9402, email dhage1@unl.edu
}

\begin{abstract}
A system based on high-performance affinity chromatography was developed for characterizing the binding, elution and regeneration kinetics of immobilized antibodies and immunoaffinity supports. This information was provided by using a combination of frontal analysis, split-peak analysis and peak decay analysis to determine the rate constants for antibody-antigen interactions under typical sample application and elution conditions. This technique was tested using immunoaffinity supports that contained monoclonal antibodies for 2,4-dichlorophenoxyacetic acid (2,4-D). Association equilibrium constants measured by frontal analysis for 2,4-D and related compounds with the immobilized antibodies were $1.7-12 \times 10^{6} \mathrm{M}^{-1}$ at $\mathrm{pH} 7.0$ and $25^{\circ} \mathrm{C}$. Splitpeak analysis gave association rate constants of $1.4-12 \times 10^{5} \mathrm{M}^{-1} \mathrm{~s}^{-1}$ and calculated dissociation rate constants of 0.01-0.4 s $\mathrm{s}^{-1}$ under the application conditions. Elution at $\mathrm{pH} 2.5$ for the analytes from the antibodies was examined by peak decay analysis and gave dissociation rate constants of $0.056-0.17 \mathrm{~s}^{-1}$. A comparison of frontal analysis results after various periods of column regeneration allowed the rate of antibody regeneration to be examined, with the results giving a first-order regeneration rate constant of $2.4 \times 10^{-4} \mathrm{~s}^{-1}$. This combined approach and the information it provides should be useful in the design and optimization of immunoaffinity chromatography and other analytical methods that employ immobilized antibodies. The methods described are not limited to the particular analytes and antibodies employed in this study but should be useful in characterizing other targets, ligands and supports.
\end{abstract}

Keywords: biointeraction analysis, immunoaffinity chromatography, high-performance affinity chromatography, split-peak analysis, peak decay analysis, frontal affinity chromatography, antibody-antigen interactions, kinetic studies

\section{Introduction}

The use of immobilized antibodies is popular in analytical techniques such as enzyme-linked immunosorbent assays (ELISAs), immunosensors, chromatographic immunoassays, and immunoaffinity chromatography [1-9]. The ability of an antibody to recognize a specific target and bind this with high affinity gives these methods good selectivity and low limits of detection [7-14]. In addition, the use of immobilized antibody supports in combination with other methods (e.g., reversedphase chromatography) has seen growing use in environmental and biological applications as a means for extracting and concentrating a given group of analytes from complex samples $[8,9,15-22]$.

The design and optimization of these techniques requires information on how the immobilized antibodies will bind and dissociate from their target compounds. Surface plasmon resonance (SPR) is one approach for obtaining equilibrium and rate constants for the binding of antibodies to these targets [23-31]; however, this method does have limitations. One limitation is that this method is restricted to materials that have appropriate optical properties for SPR measurements. In addition, SPR tends to work best for studying the binding of large analytes to an immobilized ligand because it is easiest to monitor the changes in signal under such conditions. An alternative approach that could be used to examine the binding of antibodies to a small target would be to immobilize the target and use soluble antibodies. However, this gives a system that may have different mass transfer properties and immobilization effects than a system that uses an immobilized antibody support [26-28], which could lead to errors when applying the results of thermodynamic or kinetic measurements from one system to the other.

This current report explores an alternative approach for examining the binding of analytes to immobilized antibodies by using high-performance affinity chromatography (HPAC). Like SPR, it is known that affinity chromatography can be used to obtain both kinetic and thermodynamic information on a solute-ligand interaction, but this is now accomplished by looking at the changes in elution profile of an analyte as it passes through a support containing the immobilized ligand [32-37]. Because this approach uses a post-column device to detect the analyte, there are no limitations on the type of support that can be examined; it is possible to utilize this method with the same type of material and immobilized ligand that will be used in 
the analytical method being optimized or developed. In addition, it is possible in this chromatographic approach to use a wide range of detectors (e.g., UV-vis, fluorescence, and mass spectrometry). This allows the detection of smaller analytes than in SPR and makes it easier to study the interactions of small molecules with immobilized ligands $[35,37]$.

This work will consider the development and use of an integrated approach based on affinity chromatography for examining immobilized antibody supports. The approach will be tested and illustrated by using antibodies against 2,4-dichlorophenoxyacetic acid (2,4-D) and related herbicides as a model. Items to be evaluated will include the association equilibrium constants and binding capacity of the immobilized antibodies, as well as their association and dissociation rate constants under sample application conditions. The dissociation rates of retained analytes under the column elution conditions will also be examined along with the rate of regeneration for the immobilized antibodies after sample elution. The theory behind these measurements will be discussed, and a few examples will be given that show how this information can be used to predict the performance of an immobilized antibody support when it is later employed for immunoaffinity chromatography and compound analysis.

\section{Methods}

\subsection{Reagents}

The E2/G2 monoclonal anti-2,4-D antibodies were provided by the Vet Research Center (Brno, Czech Republic) [38]. Nucleosil Si-1000 (7 $\mu \mathrm{m}$ particle diameter, 1000 A pore size) was obtained from P.J. Cobert (St. Louis, MO, USA). The 2,4-D; 2,4-dichlorophenoxyacetate methyl ester (2,4-D-Me); 2,4,5-trichlorophenoxyacetic acid (2,4,5-T); 4-chloro-2-methylphenoxyacetic acid (MCPA); and 4-chlorophenoxyacetic acid (4-CPA) were from Sigma-Aldrich (St. Louis, MO, USA). Reagents for the micro bicinchoninic acid (BCA) protein assay were from Pierce (Rockford, IL, USA). All solutions were prepared with water from a Nanopure system (Barnstead, Dubuque, IA, USA). All other reagents were of the highest grades available.

\subsection{Apparatus}

The chromatographic system consisted of ten-port and sixport Rheodyne LabPro electronically actuated valves from Alltech (Deerfield, IL, USA) along with three MicroStar pumps and one K-2500 UV-vis detector from Sonntek (Upper Saddle River, NJ, USA). Data acquisition was performed using an SCB-68 NI shielded interface and 16E series PCMCIA card from National Instruments (Austin, TX, USA). Data were collected using a Gateway Solo 2500 laptop computer (Poway, CA, USA) and analyzed with a spreadsheet prepared using Microsoft Excel (Microsoft, Redmond, WA, USA) (see Reference 39 for details on the spreadsheet).

The diol-bonded silica used in antibody immobilization was prepared from Nucleosil Si-1000 according to previous methods [40]. The coverage of diol groups on this support was found by an iodometric capillary electrophoresis assay [41] to be 38 ( \pm 7$) \mu \mathrm{mol} \mathrm{diol} / \mathrm{g}$ silica ( $\pm 1 \mathrm{SD})$. The E2/G2 monoclonal anti-2,4$\mathrm{D}$ antibodies were immobilized onto this support by the Schiff base method [42], with the immobilization being carried out at $4{ }^{\circ} \mathrm{C}$ for three days. The antibodies were added to the silica in a slurry at a ratio of $1 \mathrm{mg}$ protein/50 $\mathrm{mg}$ silica in a total volume of approximately $5 \mathrm{~mL}$. After this immobilization had been completed, the resulting antibody silica was washed several times with $\mathrm{pH} 7.0,0.1 \mathrm{M}$ potassium phosphate buffer and stored in this buffer at $4{ }^{\circ} \mathrm{C}$ until use. A small portion of the antibody silica was dried under vacuum at room temperature and assayed for its protein content by a micro BCA protein assay, with re- agent grade rabbit IgG (Sigma-Aldrich) being used as the standard. The protein coverage, as determined in triplicate by this method, was $15.9( \pm 0.2) \mathrm{mg}$ antibody/g silica.

The antibody silica was packed into a $1 \mathrm{~cm} \times 2.1 \mathrm{~mm}$ i.d. column according to a previous method [43] using a pressure of 3000 psi applied for $30 \mathrm{~min}$ and $\mathrm{pH}$ 7.0, 0.1 M potassium phosphate buffer as the packing solution. A column of equal length and diameter was packed by the same technique with Nucleosil that had been processed in a similar manner to the antibody silica but without the addition of any antibodies. This control column was used to correct for non-specific binding of analytes to the support.

\subsection{Chromatographic studies}

The samples contained $0-100 \mathrm{ng} / \mathrm{L}$ of the desired analyte in the application buffer $(\mathrm{pH} 7.0,0.1 \mathrm{M}$ potassium phosphate buffer). The elution buffer later passed through the antibody column was typically $\mathrm{pH} 2.5,0.1 \mathrm{M}$ potassium phosphate buffer, but buffers with $\mathrm{pH}$ values of $2.5-5$ were also examined. The elution of 2,4-D and all other analytes was monitored at $223 \mathrm{~nm}$. All the chromatographic studies were performed at room temperature $\left(22-25^{\circ} \mathrm{C}\right)$. All time values used in the $\mathrm{ki}$ netic measurements were corrected for the void time of the system, which was approximately $0.3 \mathrm{~min}$ at $0.4 \mathrm{~mL} / \mathrm{min}$.

Each study began by continuously applying a sample of the analyte onto both the control column and antibody column under identical flow rate and temperature conditions. These columns were originally equilibrated for $15 \mathrm{~min}$ in the application buffer before coming into contact with the analyte. Subsequent equilibration times were varied to measure the effects of regeneration time on the antibody column. After this equilibration period, the sample was continuously applied to the column until a breakthrough curve with a well-defined plateau was obtained. This typically required $5 \mathrm{~min}$ at a flow rate of $0.4 \mathrm{~mL} / \mathrm{min}$ for applied solutions of 2,4-D or the other analytes; however, at lower flow rates or more dilute analyte concentrations longer times were allowed for this step as needed. The application flow rate was varied from $0.2 \mathrm{~mL} / \mathrm{min}$ to $0.75 \mathrm{~mL} / \mathrm{min}$ during these studies, with each set of studies being performed in duplicate or triplicate. The overall breakthrough curves that were produced through this process were then analyzed to determine the binding capacities and association constants for the interaction of the analyte with the immobilized antibodies (see Section 3.2). The overall shape of these same curves, particularly in the early stages of analyte application, was used to also provide information on the rate of analyte adsorption to the immobilized antibodies (see Section 3.3).

Analyte release from the antibody column was accomplished by passing an appropriate elution buffer through the system. This caused the retained analytes to dissociate from the immobilized antibodies and leave the column. A background peak resulted during this step due to the change in buffer composition. To correct for this peak, the response obtained under the same conditions for the control column was subtracted from that for the antibody column. The background corrected results were then used to examine the dissociation kinetics of each analyte from the immobilized antibody column in the presence of the given elution buffer (see Section 3.4). The elution buffer was typically passed through these columns for $3 \mathrm{~min}$ at $0.5 \mathrm{~mL} / \mathrm{min}$; however, other studies were performed in which the elution buffer had a flow rate of $0.2-0.5 \mathrm{~mL} / \mathrm{min}$ and passed through the column for 2-5 min. The results under each set of conditions were measured at each of the concentrations used in the frontal analysis work, as described previously, and through the use of at least duplicate or triplicate studies.

Column regeneration was performed by reapplying the original application buffer to the column after the elution step. Frontal analysis was then used to see how the measured bind- 
ing capacity of the antibody column changed for $2,4-\mathrm{D}$ as a function of the regeneration time. This work was performed using various regeneration times (1.0-5.0 $\mathrm{min}$ ) and flow rates (0.5-1.5 $\mathrm{mL} / \mathrm{min})$ for washing the antibody column with $\mathrm{pH}$ 7.0, 0.1 M potassium phosphate buffer before beginning the application of analyte. After data from all of these steps had been acquired, this information was placed into a Microsoft Excel spreadsheet for data analysis and the determination of binding capacities, equilibrium constants, and rate constants, as discussed later in Section 3.

\section{Results and discussion}

\subsection{General analysis scheme}

The reaction scheme used in this study to characterize the immobilized antibodies is shown in Figure 1. This model is based on the on/off elution scheme that is commonly used in affinity chromatography for the separation and analysis of targets with strong binding to an immobilized antibody or affinity ligand $[7,14]$. A typical example of such a scheme for the immobilized antibodies that were investigated in this study is shown in Figure 2. The first step in this scheme is to apply the analyte (A) to the ligand (L) and wash away nonretained components with an application buffer. The second step involves dissociation and elution of the retained analyte in the presence of an elution buffer. Due to the large association constants that are present for most antibodies at a physiological $\mathrm{pH}$, this dissociation step generally requires the use of a $\mathrm{pH}$ step change or the addition of a modifier to alter interactions between the analyte and antibody [7, 14, 29]. The ligand is allowed to regenerate during the third step. It is during this step that an application buffer/regeneration solution is reapplied to the column, allowing the immobilized ligand to return to its initial conformation before the next sample application $[7,14]$.

In SPR, the association and dissociation events for analyteligand systems are typically examined only during the application step in Figures 1 and 2 (i.e., under reaction conditions at or near physiological conditions). The elution and regeneration steps are generally ignored in SPR during quantitative measurements and are only performed as part of the clean-up process for the sensor [29, 31] (note: dissociation kinetics can be examined by SPR when washing the surface with a buffer containing no analyte $[31,36]$ and have in some cases been examined in the presence of a different elution buffer [44]). In this current study, kinetic information generated by HPAC during both elution and regeneration was also considered as a means to provide a more complete description of the behavior of a given analyte and immobilized ligand. The overall process that was used in this report will be demonstrated in the following sections, in which the information obtained during sample application, elution and column regeneration will each be examined in turn during the characterization of an immunoaffinity support.

\subsection{Degree of analyte retention during application}

The interactions that occurred during the first step in Figures 1 and 2 (sample application) were examined by using frontal analysis (i.e., frontal affinity chromatography). In this method, a known concentration of the analyte [A] is applied to the column at a fixed flow rate while the amount of analyte exiting from the column is monitored. As the column becomes saturated, this process results in a breakthrough curve in which the mean position of this curve is related to the binding capacity of the column. For monoclonal antibodies or ligands with single-site binding, this data can be examined using the following equation [35],

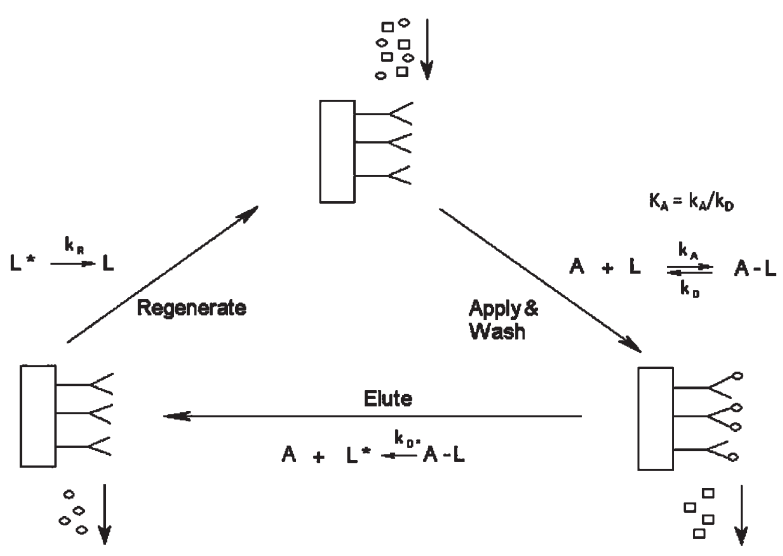

Figure 1. General kinetic processes used in this study to model the binding and elution of an analyte in affinity chromatography. In this model, $k_{\mathrm{A}}$ and $k_{\mathrm{D}}$ are the association and dissociation rate constants for analyte-antibody interactions during sample application, $k_{\mathrm{D}^{*}}$ is the first-order dissociation rate constant describing analyte elution, and $k_{\mathrm{R}}$ is the first-order rate constant that describes the regeneration of the immobilized antibodies.

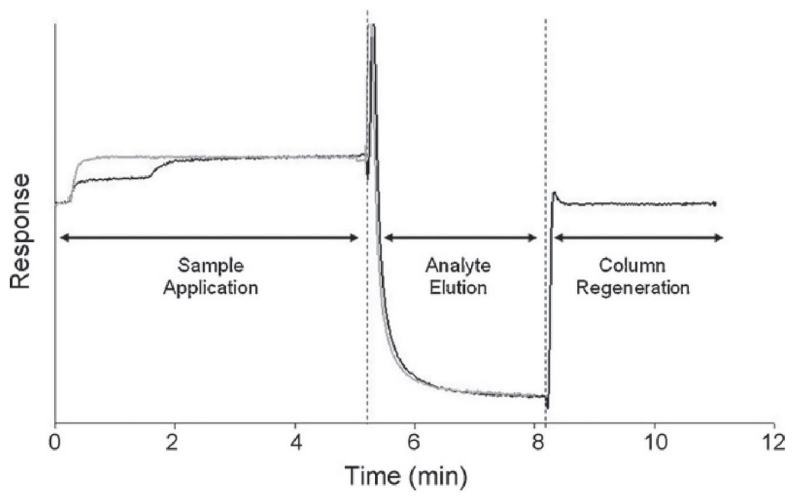

Figure 2. A typical chromatogram obtained in this study for the examination of analyte binding and elution from an immunoaffinity column. The lighter line shows a chromatographic performed on a control column containing no antibodies, while the heavier line gives the results obtained for analytes on an immobilized antibody support.

$$
\frac{1}{\left(m_{\mathrm{L}, \mathrm{app}}\right)}=\frac{1}{\left(m_{\mathrm{L}} K_{\mathrm{A}}[\mathrm{A}]\right)}+\frac{1}{m_{\mathrm{L}}}
$$

where $K_{\mathrm{A}}$ is the association equilibrium constant for the binding of $\mathrm{A}$ to the immobilized ligand, $m_{\mathrm{L} \text {,app }}$ is the apparent moles of analyte required to reach the mean position of the resulting breakthrough curve at a given concentration of applied analyte [A], and $m_{\mathrm{L}}$ is the total mole of binding sites in the column for A. Equation (1) indicates that a plot of $1 /\left(m_{\mathrm{L}, \text { app }}\right)$ versus $1 /[\mathrm{A}]$ for a homogeneous system with 1:1 binding should give a straight line with a slope equal to $1 /\left(m_{\mathrm{L}} K_{\mathrm{A}}\right)$ and an intercept equal to $1 /\left(m_{\mathrm{L}}\right)$. The binding capacity can then be obtained by taking the reciprocal of the intercept, and an estimate of the association equilibrium constant can be obtained by dividing the intercept by the slope.

Equation (1) works well for ligands with weak-to-moderate affinities but can also be used for high affinity ligands if measurable dissociation is present, thus allowing the creation of a local equilibrium at the mean point of the breakthrough curve. For antibodies, typical association constants are often in the range of $10^{5}-10^{12} \mathrm{M}^{-1}$. Equation (1) is particularly useful for monoclonal antibodies, which tend to have association equilibrium constants at the lower end of this range $\left(K_{\mathrm{A}}<10^{9} \mathrm{M}^{-1}\right)$; however, even with higher affinity ligands the intercept of Equation (1) can be used to provide an estimate of the total binding capacity for an affinity column. 


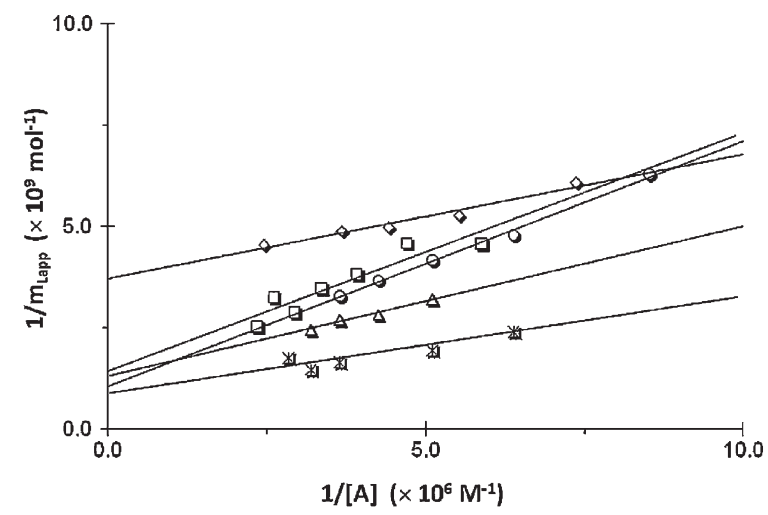

Figure 3. Analysis of the association equilibrium constants for several compounds as they were bound by immunoaffinity columns containing immobilized anti-2,4-D antibodies. These data were analyzed according to Equation (1) for 2,4-D ( $\diamond)$, 2,4-D-Me ( $\square$ ), 2,4,5-T ( $\Delta$ ), 4-CPA $(\circ)$, and MCPA $\left(^{*}\right)$, giving correlation coefficients of $0.96,0.86,0.98$, 0.99 and 0.93 , respectively. Each of the data points shown in this plot is the average for duplicate or triplicate measurements. Part of the difference in the intercepts of these particular plots (e.g., the 2,4-D results versus 2,4-D-Me) is a result of loss of some activity over time for the immunoaffinity columns.

Figure 3 shows some typical plots that were obtained in this study when the mean positions of frontal analysis curves for anti-2,4-antibody supports were analyzed according to Equation (1) [35]. As shown in this figure, plots of $1 / m_{\mathrm{L} \text {,app }}$ versus $1 /[\mathrm{A}]$ were found to give reasonably good agreement with a linear fit for the various analytes that were tested under the application conditions used in this study. The slopes and intercepts of these plots were then used with Equation (1) to obtain the total binding capacity $\left(m_{\mathrm{L}}\right)$ and association equilibrium constant $\left(K_{\mathrm{A}}\right)$ of the immobilized antibodies for each of the applied analytes.

The original binding capacity obtained for 2,4-D on this

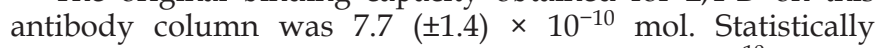
equivalent or similar values ranging from $7 \times 10^{-10} \mathrm{~mol}$ to $12 \times 10^{-10} \mathrm{~mol}$ were obtained for the related analytes that were tested (i.e., 2,4-D-Me; 2,4,5-T; 4-CPA; and MCPA). Based on the measured protein content of the support in this column (15.9 mg antibody/g silica) and the known packing density of the support $\left(0.45 \mathrm{~g} / \mathrm{cm}^{3}\right)$, the total antibody content of this column was estimated to be $3.4 \times 10^{-9}$ mol. This meant that $34-$ $49 \%$ of these antibodies retained their activity for binding to 2,4-D and related compounds after immobilization, as based on a 1:1 binding model.

The linear behavior noted for the plots in Figure 3 indicated that Equation (1) could be used to obtain the association equilibrium constants for the anti-2,4-D column with each of the tested analytes. Using this approach, it was found for the five related but distinct compounds examined in this study that the resulting association equilibrium constants ranged from $1.7 \times 10^{6} \mathrm{M}^{-1}$ to $12 \times 10^{6} \mathrm{M}^{-1}$ under the application conditions, as summarized in Table 1 . The differences in these values indicate that slightly different interactions are occurring between each of these compounds and the immobilized anti-2,4-D

Table 1. Association equilibrium constants and association/dissociation rate constants of anti-2,4-D monoclonal antibodies at pH 7.0 and $25^{\circ} \mathrm{C}^{\mathrm{a}}$.

\begin{tabular}{lccl}
\hline Analyte & $K_{\mathrm{A}}\left(\times 10^{6} \mathrm{M}^{-1}\right)$ & $k_{\mathrm{A}}\left(\times 10^{5} \mathrm{M}^{-1} \mathrm{~s}^{-1}\right)$ & $k_{\mathrm{D}}\left(\mathrm{s}^{-1}\right)$ \\
\hline 2,4-D & $12.0( \pm 1.0)$ & $3.4( \pm 0.7)$ & $0.028( \pm 0.006)$ \\
MCPA & $11.8( \pm 2.7)$ & $1.4( \pm 0.5)$ & $0.012( \pm 0.005)$ \\
2,4,5-T & $3.4( \pm 0.5)$ & $12.0( \pm 2.0)$ & $0.36( \pm 0.08)$ \\
2,4-D-Me & $2.4( \pm 0.8)$ & $4.1( \pm 0.8)$ & $0.17( \pm 0.07)$ \\
4-CPA & $1.7( \pm 0.3)$ & $2.6( \pm 0.7)$ & $0.15( \pm 0.05)$ \\
\hline
\end{tabular}

a The values for $K_{\mathrm{A}}, k_{\mathrm{A}}$, and $k_{\mathrm{D}}$ were calculated as described in text. The numbers shown in parentheses represent a range of $\pm 1 \mathrm{SD}$. column; however, this overall range of values is typical of what would be expected for monoclonal antibodies and are well within the range of equilibrium constants that are amenable to measurement by frontal analysis. The result of 12.0 $( \pm 1.0) \times 10^{6} \mathrm{M}^{-1}$ obtained for 2,4 -D is comparable, although not statistically identical, to previous measurements performed with the same antibodies using a quartz crystal microbalance, in which 2,4-D was found to have an association constant of $5.75 \times 10^{6} \mathrm{M}^{-1}$ in the presence of $\mathrm{pH} 7.0,0.05 \mathrm{M}$ phosphate buffer [38]. The approximately two-fold difference in these latter values may have been due to differences in the particular solution and measurement conditions or in the immobilization methods that were used in these two studies [7].

It was possible from the measured binding capacities and association equilibrium constants to estimate the retention factor $(k)$ for each analyte on the immunoaffinity support under the application conditions. This value was calculated by using the relationship $k=\left(K_{\mathrm{A}} m_{\mathrm{L}}\right) / V_{\mathrm{M}}$, where $V_{\mathrm{M}}$ is the void volume of the column. Using an average initial binding capacity of $8 \times 10^{-10} \mathrm{~mol}$ gave a retention factor at $\mathrm{pH} 7.0$ and $25^{\circ} \mathrm{C}$ that was greater than 330 for 2,4-D and MCPA and retention factors that were between roughly 50 and 100 for the other analytes. The results for 2,4-D and MCPA represented reasonably strong retention. For instance, at $0.5 \mathrm{~mL} / \mathrm{min}$ a small plug of $2,4-\mathrm{D}$ or MCPA would require at least $18-20 \mathrm{~min}$ to pass through the immunoaffinity column under the application conditions. This result indicated that the given anti-2,4-D antibody columns could be successfully used to extract and retain 2,4-D and MCPA from samples. The other tested analytes would have retention times ranging from $2.8 \mathrm{~min}(4-\mathrm{CPA})$ to $5.5 \mathrm{~min}(2,4,5-\mathrm{T})$ under the same conditions. Careful control of the application and wash step could also allow the anti-2,4-D antibody column to be used for the immunoextraction of these agents, as has been demonstrated in recent simulations of immunoaffinity/reversed-phase systems [22] and in past work examining the binding of anti-atrazine immunoaffinity columns for triazine herbicides and their degradation products $[10,21]$.

\subsection{Kinetics of analyte retention}

The association and dissociation kinetics of each analyte during the application step were also examined in this study. If the support is an efficient material with relatively fast mass transfer from the bulk solution to the surface or interior of the support, the rate of capture of the analyte during application process can be modeled by using an adsorption-limited process $[35,37]$. The situation occurs when the rate of binding is limited by the association of the molecule to the antibody. This type of reaction has been successfully used in the past to describe the adsorption of analytes to HPLC-based immunoaffinity supports (e.g., see Reference [32]). This process is described in Figure 1 by a second-order adsorption rate constant $\left(k_{\mathrm{A}}\right)$ and a first-order dissociation rate constant $\left(k_{\mathrm{D}}\right)$.

One way in which the rate of this binding can be measured is by measuring the fraction $f$ of the analyte that is non-retained or "free" at various flow rates [32-34, 37, 45-46]. Under adsorption-limited conditions and in the case where the rate of analyte dissociation is slow and negligible versus analyte adsorption, this free and non-retained fraction can be related to the flow rate $(F)$, association rate constant, number of active binding sites in the column, and amount of applied analyte, as shown in Equation (2) [32].

$$
\left.f=\left\{\frac{S_{\mathrm{o}}}{\operatorname{Load} \mathrm{A}}\right\} \ln \left[1+\mathrm{e}^{\operatorname{LoadA} / S_{\mathrm{o}}}-1\right) \mathrm{e}^{-1 / S_{\mathrm{o}}}\right]
$$

In this equation, the term $S_{\mathrm{o}}$ is equal to $F /\left(k_{\mathrm{A}} m_{\mathrm{L}}\right)$ and Load $\mathrm{A}$ is the ratio of the moles of applied analyte compared to the moles of binding sites in the column, where Load $\mathrm{A}=(\mathrm{mol}$ 


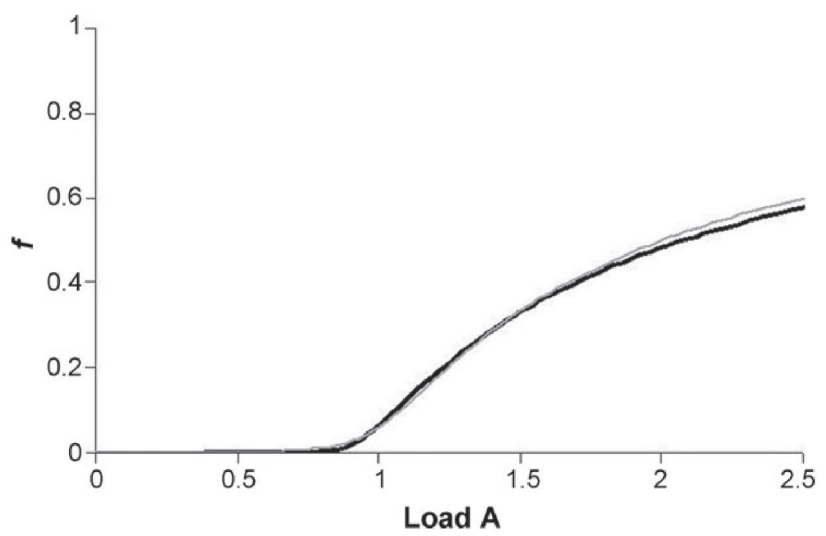

Figure 4. Fit between the experimental results and those predicted by Equation (2) for the application of a $100 \mathrm{ppb}$ solution of 2,4,5-T to an immobilized anti-2,4-D antibody column. The values of both $f$ and Load $\mathrm{A}$ are unitless, as indicated by the definitions of these terms in the text.

A) $/ m_{\mathrm{L}}$. Using Equation (2), non-linear application conditions can be used to calculate the value of $k_{\mathrm{A}}$ for an immobilized antibody if the flow rate, amount of applied sample and binding capacity of the column are known. Equation (2) can also be used to estimate the binding capacity of the column, but in this study the binding capacity was instead obtained by using Equation (1), as described in the previous section, to reduce the number of variables that are present during the measurement of $k_{\mathrm{A}}$ (note: alternative kinetic methods based on fitting a frontal analysis profile are also available, as discussed in References 37 and 47-49).

As shown in Figure 4, a good fit was found for all analytes between Equation (2) and the early part of a frontal analysis curve for the immunoaffinity column (i.e., conditions under which analyte dissociation was essentially negligible; similar behavior has been seen for the methods described in References 37 and 47-49). The best fit in this response occurred between Load A values of $0-2$. The average deviations over this range between the predicted and experimental free fraction curves, as generated according to Equation (2), varied from 1.9\% to $16 \%$ for the various analytes that were examined in this report. The association rate constants determined from these curves (see Table 1) varied from $1.4 \times 10^{5} \mathrm{M}^{-1} \mathrm{~s}^{-1}$ to $12 \times 10^{5} \mathrm{M}^{-1} \mathrm{~s}^{-1}$ for binding of the immobilized 2,4-D antibodies to the targets examined in this work. The dissociation rate constants under the application conditions were then calculated by using both these measured association rate constants and the $K_{\mathrm{A}}$ values determined in the previous section, as given by the relationship $K_{\mathrm{A}}=k_{\mathrm{A}} / k_{\mathrm{D}}$. These dissociation rate constants are also listed in Table 1 and ranged from $0.012 \mathrm{~s}^{-1}$ to $0.36 \mathrm{~s}^{-1}$.

A previous report using a piezoelectric quartz crystal microbalance (QCM) gave an association rate constant of 4.5 $( \pm 0.3) \times 10^{3} \mathrm{M}^{-1} \mathrm{~s}^{-1}$ in the binding of 2,4-D to the same antibodies as used in this report but using immobilized 2,4-D and soluble antibodies [38]. However, it was found in this current study that using immobilized antibodies and soluble 2,4-D gave an association rate constant of $3.4( \pm 0.7) \times 10^{5} \mathrm{M}^{-1} \mathrm{~s}^{-1}$. This can be explained based on the fact that the rate of antibody binding tends to be diffusion-limited. In the case of the piezoelectric QCM, diffusion would have been much slower since a large biomolecule (i.e., an antibody) had to diffuse to the sensor surface before it could bind to the immobilized 2,4-D. However, in this current study a faster rate of binding would have been expected since a small target (2,4-D) was now diffusing to a surface which contained the immobilized antibodies. This difference indicates the importance of using the same support material and immobilized agent in such kinetic studies as will be used in the final desired application of such substances.

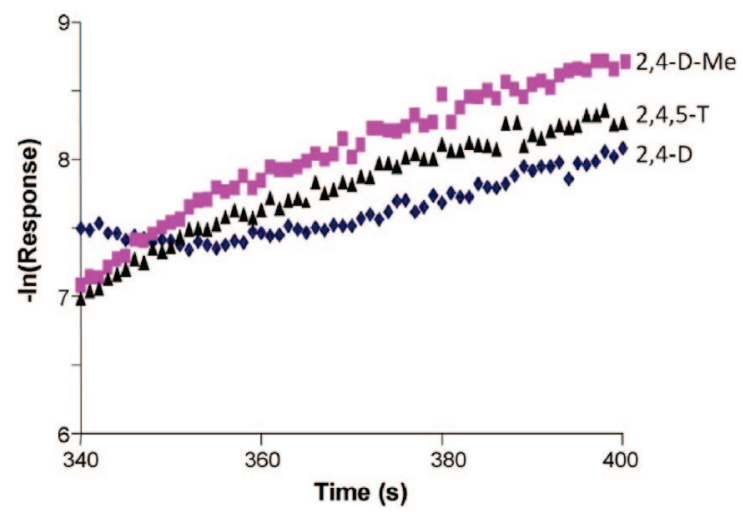

Figure 5. First-order kinetic plots prepared according to Equation (5) for the elution of several analytes from immobilized anti-2,4-antibodies in the presence of $\mathrm{pH} 2.5,0.10 \mathrm{M}$ phosphate buffer. The "response" used in the logarithmic term on the $y$-axis was determined by using the absorbance measurements obtained for the elution profile after subtracting the elution profile for the same analyte from the blank column.

\subsection{Kinetics of analyte elution}

The rate of release of a retained analyte during elution (i.e., Step 2 in Figure 1) was also considered in this work. The rate of release for an analyte from a high affinity ligand (e.g., an antibody) when using a step gradient can be described as a first-order process,

$$
\mathrm{A}-\mathrm{L}^{*} \underset{k_{\mathrm{A}^{*}}}{\stackrel{k_{\mathrm{D}_{*}}}{\rightleftarrows}} \mathrm{A}^{*}+\mathrm{L}^{*}
$$

where $L^{*}, A^{*}$, and $A-L^{*}$ represent the ligand, analyte, and analyte-ligand complex in the presence of the elution buffer, and $k_{\mathrm{D}^{*}}$ and $k_{\mathrm{A}^{*}}$ are the dissociation and association rate constants for the $\mathrm{A}-\mathrm{L}^{*}$ under these conditions. If $\mathrm{A}^{*}$ is removed quickly from the column during elution and not allowed to rebind to the immobilized ligand, the association of $A^{*}$ with $L^{*}$ can be ignored in the above reaction. The remaining dissociation process can then be described by the following first-order rate law and integrated rate expression [37, 50-52],

$$
\begin{aligned}
& \frac{-\mathrm{d}\left[\mathrm{A}-\mathrm{L}^{*}\right]}{\mathrm{d} t}=\frac{\mathrm{d}\left[\mathrm{A}^{*}\right]}{\mathrm{d} t}=k_{\mathrm{D}^{*}}\left[\mathrm{~A}^{*}\right] \\
& \ln \left[\mathrm{A}^{*}\right]=-k_{\mathrm{D}^{*}} t+\ln \left[\mathrm{A}^{*}\right]_{0}
\end{aligned}
$$

where $t$ is the time allowed for elution and $\left[\mathrm{A}^{*}\right]_{0}$ is the amount of $A^{*}$ initially present in the system. According to Equation (5), a plot of $\ln \left[\mathrm{A}^{*}\right]$ versus $t$ should be linear during elution with a slope equal to $-k_{\mathrm{D}^{*}}$, the dissociation rate constant. Linearization of the signal versus time has been used to determine the rate constants of many systems [50-55], and is adequate for calculating the dissociation rate constant for a system based on a simple bimolecular interaction such as the release of analyte from the antibody used in this model system [37, 50-52].

The results obtained for 2,4-D and related herbicides are shown in Figure 5. This elution was found to give a good fit with a first-order decay process with effective dissociation rate constants of $0.06-0.176 \mathrm{~s}^{-1}$ being obtained for the given analytes in the presence of $\mathrm{pH} 2.5,0.10 \mathrm{M}$ phosphate buffer. Although a good fit was noted between these elution profiles and the first-order model, there was a decrease of $(20-50 \%)$ noted in these apparent dissociation rate constants when the flow rate was decreased below $0.4-0.5 \mathrm{ml} / \mathrm{min}$. This is believed to be due to a greater chance of reentry of the analytes in the pores of the support at low flow rates. It was also possible with this method to examine how the dissociation rate constant changed with elution $\mathrm{pH}$. This result is summarized 


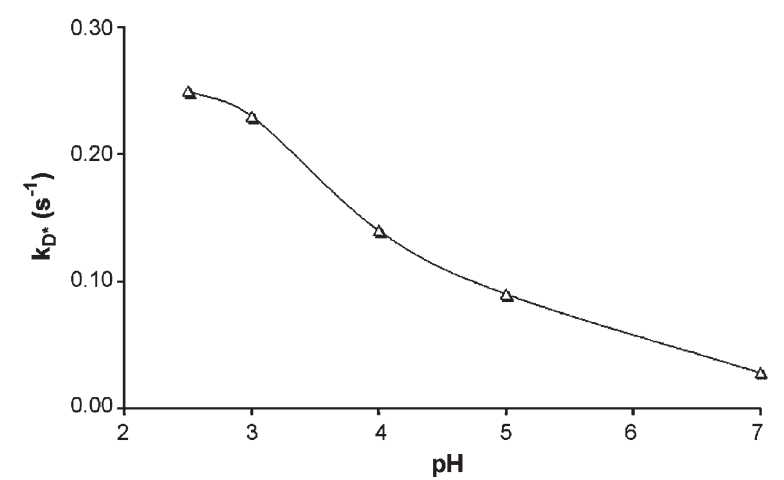

Figure 6. Change in the measured dissociation rate constant with $\mathrm{pH}$ for the elution of 2,4-D from an immunoaffinity column containing anti-2,4-D-antibodies. Each of the data points shown in this plot is the average for duplicate or triplicate measurements.

in Figure 6, where much faster elution was noted for 2,4-D as well as all related compounds from the anti-2,4-D antibodies as a change was made from a neutral to acidic elution $\mathrm{pH}$.

These dissociation rate constants were also used to calculate the amount of time required to recover a given fraction of an applied analyte from the immunoaffinity column. For instance, when the anti-2,4-D antibody column is saturated, the initial amount of 2,4-D on the column is approximately equal to the binding capacity, or $2.4 \times 10^{-10} \mathrm{~mol}$. If the dissociation rate constant of the antibody column for 2,4-D is $0.145 \mathrm{~s}^{-1}$ under the given elution conditions (e.g., $\mathrm{pH} 2.5$ ), $90 \%$ of the 2,4-D will be recovered within $15.8 \mathrm{~s}$. A recovery of $95 \%$ or $99 \%$ will take $20.7 \mathrm{~s}$ or $31.8 \mathrm{~s}$, respectively. These results indicate that elution of essentially all the 2,4-D will take place in less than $1 \mathrm{~min}$. The 2,4-D-Me would require elution over $28.8 \mathrm{~s}, 37.5 \mathrm{~s}$ or $57.6 \mathrm{~s}$ for $90 \%, 95 \%$ or $99 \%$ recovery; for $2,4,5-\mathrm{T}$ the times required to obtain the same recoveries would be $24.5 \mathrm{~s}, 31.9 \mathrm{~s}$ and $49.0 \mathrm{~s}$. This information is helpful in ensuring that a high degree of each analyte has been dissociated from the immunoaffinity support. A high recovery during elution is desirable to increase the signal that is obtained for each analyte and to minimize carryover effects when the immunoaffinity support is to be used over many sample injections.

\subsection{Kinetics of column regeneration}

The rate of regeneration for antibodies is another important issue to consider if the same support is to be used for multiple assays. In this study, the rate of regeneration was examined by plotting the measured binding capacity of the column after regeneration versus the time allowed for regeneration of the column. Regeneration of antibodies after dissociation of analyte has occurred in the presence of an elution buffer may require the reformation of intra-molecular bonds. This regeneration is typically accomplished by returning the immunoaffinity support to its initial application buffer. It is important to determine the amount of time and/or solvent that is needed to return the antibody to its original conformation during the regeneration step because the rate of this process can affect both the speed with which an assay can be conducted by immunoaffinity chromatography and the practical lifetime of an immunoaffinity support.

Regeneration of an immunoaffinity support was modeled in this work by using the following first-order reaction,

$$
\mathrm{L}^{*} \underset{k_{-\mathrm{R}}}{\stackrel{k_{\mathrm{R}}}{\rightleftarrows}} \mathrm{L}
$$

where $\mathrm{L}^{*}$ is the immobilized ligand in the dissociation state and $L$ is the immobilized ligand in the binding state (see Figure

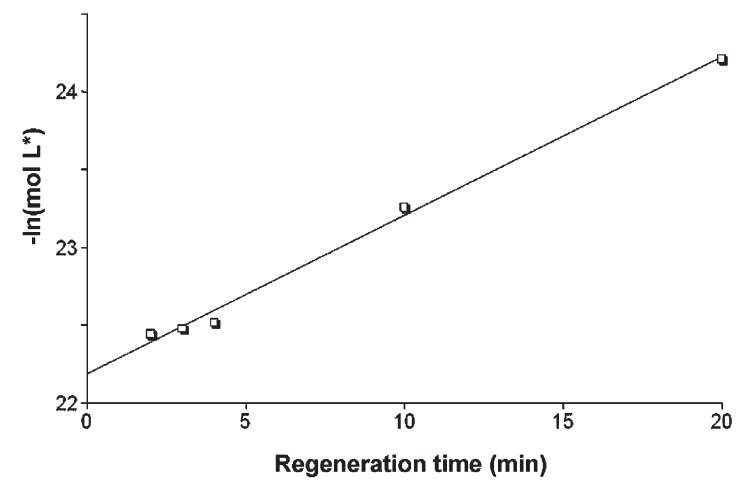

Figure 7. Determination of the rate of regeneration for the immobilized anti-2,4-D antibodies in going from $\mathrm{pH} 2.5,0.10 \mathrm{M}$ phosphate buffer to $\mathrm{pH} 7.0,0.1 \mathrm{M}$ phosphate buffer at a flow rate of $0.5 \mathrm{~mL} / \mathrm{min}$. Each of the data points shown in this plot is the average for duplicate or triplicate measurements.

1). As a first-order kinetic process, the regeneration rate that would be expected for this reaction is described by Equation (7).

$$
\frac{-\mathrm{d}\left[\mathrm{L}^{*}\right]}{\mathrm{d} t}=\frac{\mathrm{d}[\mathrm{L}]}{\mathrm{d} t}=k_{\mathrm{R}}\left[\mathrm{L}^{*}\right]+k_{-\mathrm{R}}[\mathrm{L}]
$$

Assuming that the rate of the back reaction is negligible, the last term in Equation (7) goes to zero and the rate law becomes

$$
\frac{-\mathrm{d}\left[\mathrm{L}^{*}\right]}{\mathrm{d} t}=k_{\mathrm{R}}\left[\mathrm{L}^{*}\right] \quad \text { or } \quad \frac{-\mathrm{d}\left(\mathrm{mol} \mathrm{L}^{*}\right)}{\mathrm{d} t}=k_{\mathrm{R}}\left(\mathrm{mol} \mathrm{L}^{*}\right)
$$

which can be integrated to give the expressions in Equation (9).

$$
\ln \left[\mathrm{L}^{*}\right]=-k_{\mathrm{R}} t+\ln \left[\mathrm{L}^{*}\right]_{0} \text { or } \ln (\mathrm{mol} \mathrm{L})=-k_{\mathrm{R}} t+\ln (\mathrm{mol} \mathrm{L})_{0}
$$

This result indicates that a plot of $-\ln \left[\mathrm{L}^{*}\right]$ or $-\ln \left(\mathrm{mol} \mathrm{L}^{*}\right)$ versus regeneration time will provide a straight line with a slope of $k_{\mathrm{R}}$ and an intercept of $\ln \left[\mathrm{L}^{*}\right]_{0}$ or $\left.\ln (\mathrm{mol} \mathrm{L})_{0}\right)_{0}$ if antibody regeneration follows a first-order process.

The results that were obtained when this model was used to examine the experimental data are shown in Figure 7. It was found that a reasonable linear fit to Equation (9) was obtained, giving a correlation coefficient of 0.995 . From this fit, the rate constant for antibody regeneration was determined to be 2.4 $( \pm 0.3) \times 10^{-4} \mathrm{~s}^{-1}$. It was determined from this result that $95 \%$ of the binding sites in the column were regenerated in less than 1 min when using a step change from a pH 2.5 elution buffer to a pH 7.0 application buffer. This information could be valuable in designing an immunoaffinity system that is to be used over a large number of sequential injection, elution and regeneration cycles. The intercept of Figure 7 made it possible to estimate the initial amount of active binding sites that must have been present prior to regeneration with the anti-2,4-D antibody column. This estimated value was $6.3( \pm 0.1) \times 10^{-10} \mathrm{~mol}$, which was comparable to the original binding capacity of $7-12 \times 10^{-10} \mathrm{~mol}$ that was measured for the same immunoaffinity support by frontal analysis (see Section 3.2).

\section{Conclusions}

It was found in this study that the direct use of affinity chromatography is an effective and inexpensive method for determining equilibrium and rate constants for the binding of small molecules to monoclonal antibodies. This allowed information to be obtained on the application, elution and regeneration kinetics of immobilized antibodies. This technique was tested using HPLC supports containing monoclonal antibodies for 2,4-D. Association equilibrium constants measured for 2,4-D and related compounds were 1.7-12 × $10^{6} \mathrm{M}^{-1}$ at $\mathrm{pH} 7.0$ 
and $25{ }^{\circ} \mathrm{C}$, with association and dissociation rate constants of $1.4-12 \times 10^{5} \mathrm{M}^{-1} \mathrm{~s}^{-1}$ and $0.01-0.4 \mathrm{~s}^{-1}$. Release of analytes from these antibodies at pH 2.5 followed a first-order decay model, with dissociation rate constants of $0.056-0.17 \mathrm{~s}^{-1}$. Regeneration of the immobilized antibodies also followed a first-order process, with a regeneration rate constant of $2.4 \times 10^{-4} \mathrm{~s}^{-1}$.

It was shown how the information that was obtained in this study can be useful in the design and optimization of analysis methods employing immobilized antibodies. For instance, the binding capacities and association equilibrium constants determined by frontal analysis can be used to determine the overall degree of retention for an analyte under the sample application conditions. Association rate constants can be used to determine the rate of analyte extraction, and dissociation rate constants can be used to predict the rate of analyte release under a given set of elution conditions. The extent of column regeneration can also be optimized by this approach.

The methods described in this study are not limited to the given analytes and antibodies but should also be useful in kinetic studies with other types of targets, ligands and supports. This approach allows all aspects of the sample application, elution and regeneration cycle to be examined for an immunoaffinity support. It should also be possible to use this approach with a wider variety of support materials and surfaces than can be currently examined by SPR. In addition, this chromatographic approach to kinetic studies can be adapted for use with a variety of detectors (i.e., as has already been demonstrated for immunoaffinity chromatography in general) [7, $8,14]$, making it easier to use than SPR with dilute analytes or those that do not produce a large change in signal as they bind to the surface of an SPR sensor. All of these features make this approach an attractive alternative to SPR for the direct characterization of immunoaffinity materials and for kinetic studies of immobilized biological molecules.

\section{Acknowledgments}

This work was supported, in part, by an exploratory grant through the U.S. Environmental Protection Agency and by the National Institutes of Health under grant RO1 GM044391. These studies were conducted in facilities renovated under NIH grant RR015468-01.

\section{References}

[1] J. E. Butler, J. Immunol. 21 (2000), p. 165.

[2] H. A. Moye, Chem. Anal. 151 (1999), p. 211.

[3] D. M. Kemeny, Methods Mol. Med. 12 (1998), p. 257.

[4] B. Nilsson, Curr. Opin. Immunol. 2 (1990), p. 898.

[5] D. M. Kemeny, Immunochemistry 1 (1997), p. 147.

[6] K. Makarananda and G. E. Neal, Methods Mol. Biol. 10 (1992), p. 267.

[7] D. S. Hage and T. M. Phillips in D. S. Hage, ed., Handbook of Affinity Chromatography (2nd ed.), CRC Press, Taylor and Francis, New York (2006) (Chapter 6).

[8] D. S. Hage and M. A. Nelson, Anal. Chem. 73 (2001), p. 198A.

[9] In J. M. Van Emon, Editor, Immunoassay and Other Bioanalytical Techniques, CRC Press/Taylor and Francis, New York (2007).

[10] J. G. Rollag, M. Beck-Westermeyer, and D. S. Hage, Anal. Chem. 68 (1996), p. 3631.

[11] M. Cichna, P. Markl, D. Knopp, and R. Niessner, J. Chromatogr. A 919 (2001), p. 51

[12] K. A. Bean and J. D. Henion, J. Chromatogr. A 791 (1997), p. 119.

[13] D. S. Hage, Clin. Chem. 45 (1999), p. 593.

[14] D. S. Hage, J. Chromatogr. B 715 (1998), p. 3.

[15] B. Hock, A. Marx, M. Seifert, and G. Brenner-Weiss, Quim. Anal. 17 (1998), p. 185.

[16] J. Sherry, Chemosphere 34 (1997), p. 1011.
[17] J. M. Van Emon, C. L. Gerlach, and K. Bowman, J. Chromatogr. B 715 (1998), p. 211.

[18] J. M. Van Emon, C. L. Gerlach, and K. L. Bowman, ACS Sym. Ser. 747 (2000), p. 23.

[19] C. L. Flurer and M. Novotny, Anal. Chem. 65 (1993), p. 817.

[20] C. A. C. Wolfe, W. Clarke, and D. S. Hage in D. S. Hage, ed., Handbook of Affinity Chromatography (2nd ed.), CRC Press, Taylor and Francis, New York (2006) (Chapter 17).

[21] M. A. Nelson, A. Gates, M. Dodlinger, and D. S. Hage, Anal. Chem. 76 (2004), p. 805.

[22] M. A. Nelson, E. Papastavros, M. Dodlinger, and D. S. Hage, J. Agric. Food Chem. 55 (2007), p. 3788.

[23] M. Brigham-Burke, J. R. Edwards, and D. J. O'Shannessy, Anal. Biochem. 205 (1992), p. 125.

[24] D. J. O'Shannessy, M. Brigham-Burke, K. K. Soneson, P. Hensley, and I. Brooks, Methods Enzymol. 240 (1994), p. 323.

[25] D. J. O'Shannessy, Curr. Opin. Biotechnol. 5 (1994), p. 65.

[26] R. Karlsson and R. Stahlberg, Anal. Biochem. 228 (1995), p. 274.

[27] D. R. Hall, J. R. Cann, and D. J. Winzor, Anal. Biochem. 235 (1996), p. 175.

[28] D. J. O'Shannessy and D. J. Winzor, Anal. Biochem. 236 (1996), p. 275.

[29] K. Andersson, M. Haemaelaeinen, and M. Malmqvist, Anal. Chem. 71 (1999), p. 2475.

[30] H. Saunal, R. Karlsson, and M. H. V. Van Regenmortel, Immunochemistry 2 (1997), p. 1.

[31] S. D. Long and D. G. Myszka in D. S. Hage, ed., Handbook of Affinity Chromatography (2nd ed.), CRC Press, Taylor and Francis, New York (2006) (Chapter 25).

[32] D. S. Hage, D. H. Thomas, and M. S. Beck, Anal. Chem. 65 (1993), p. 1622.

[33] J. Renard and C. Vidal-Madjar, J. Chromatogr. A 661 (1994), p. 35.

[34] D. S. Hage and R. R. Walters, J. Chromatogr. 436 (1988), p. 111.

[35] D. S. Hage and J. Chen in: D. S. Hage, ed., Handbook of Affinity Chromatography (2nd ed.), CRC Press, Taylor and Francis, New York (2006) (Chapter 22).

[36] D. J. Winzor in: D. S. Hage, ed., Handbook of Affinity Chromatography (2nd ed.), CRC Press, Taylor and Francis, New York (2006) (Chapter 23).

[37] J. E. Schiel, D. S. Hage, J. Sep. Sci., in press.

[38] M. Franek, V. Kolar, M. Granatova, and Z. Nevorankova, J. Agric. Food Chem. 42 (1994), p. 1369.

[39] M. A. Nelson, Studies of Portable Immunochromatographic Methods for Analysis of Pesticide Residues, Ph. D. dissertation, University of Nebraska-Lincoln, Lincoln, NE, 2003.

[40] R. R. Walters, J. Chromatogr. 249 (1982), p. 19.

[41] A. Chattopadhyay and D. S. Hage, J. Chromatogr. A 758 (1997), p. 255.

[42] P. O. Larsson, Methods Enzymol. 104 (1984), p. 212.

[43] W. Clarke and D. S. Hage, Anal. Chem. 73 (2001), p. 1366.

[44] R. L. Rich, Y. S. N. Day, T. A. Morton, and D. G. Myszka, Anal. Biochem. 296 (2001), p. 197.

[45] D. H. Thomas, M. Beck-Westermeyer, and D. S. Hage, Anal. Chem. 66 (1994), p. 3823.

[46] J. C. Giddings and H. Eyring, J. Phys. Chem. 59 (1955), p. 416.

[47] Q. M. Mao, A. Johnston, J. G. Prince, and T. W. Hearn, J. Chromatogr. 548 (1991), p. 147.

[48] J. Renard, C. Vidal-Madiar and C. Lapresle, J. Colloid Interface Sci. 174 (1995), p. 61.

[49] S. Golshan-Shirazi and G. Guichon, J. Chromatogr. 603 (1992), p. 1.

[50] K. Bondeson, A. Frostell-Karlsson, L. Faegerstam, and G. Magnusson, Anal. Biochem. 214 (1993), p. 245.

[51] R. R. Walters in I. M. Chaiken, ed., Analytical Affinity Chromatography, CRC Press, Boca Raton (1987), p. 117.

[52] R. M. Moore and R. R. Walters, J. Chromatogr. 384 (1987), p. 91.

[53] B. S. Wang, H. Sadeghi, C. Fung, K. Korkidis, and A. L. Lumanglas, Mol. Cell. Endocrinol. 92 (1993), p. 161.

[54] B. C. Cunningham and J. A. Wells, J. Mol. Biol. 234 (1993), p. 554.

[55] T. A. Morton et al., J. Mol. Recognit. 7 (1994), p. 47. 